\title{
Difference Between Signet Ring Cell Gastric Cancers and Non-Signet Ring Cell Gastric Cancers: A Systematic Review and Meta-Analysis
}

\section{OPEN ACCESS}

Edited by:

Laura Lorenzon,

Catholic University of the Sacred

Heart, Italy

Reviewed by:

Lei Zhang,

Sun Yat-Sen Memorial Hospital, China

Mirko Omejc,

University of Ljubljana, Slovenia

${ }^{*}$ Correspondence:

Jian-Kun Hu

hujkwch@126.com

Wei-Han Zhang

weihanzhang@scu.edu.cn

tThese authors have contributed equally to this work

¥These authors jointly supervised this work

Specialty section:

This article was submitted to Gastrointestinal Cancers,

a section of the journal

Frontiers in Oncology

Received: 17 October 2020

Accepted: 22 February 2021

Published: 07 May 2021

Citation:

Zhang $C$, Liu R, Zhang $W-H$, Chen $X-Z$, Liu K, Yang $K$, Chen $X-L$,

Zhao L-Y, Chen Z-X, Zhou Z-G and

Hu J-K (2021) Difference Between

Signet Ring Cell Gastric Cancers and

Non-Signet Ring Cell Gastric Cancers:

A Systematic Review and

Meta-Analysis.

Front. Oncol. 11:618477.

doi: 10.3389/fonc.2021.618477
Chi Zhang ${ }^{1+}$, Ran Liu ${ }^{2+}$, Wei-Han Zhang ${ }^{1 \neq \neq}$, Xin-Zu Chen ${ }^{1}$, Kai Liu ${ }^{1}$, Kun Yang ${ }^{1}$, Xiao-Long Chen ${ }^{1}$, Lin-Yong Zhao ${ }^{1}$, Zhi-Xin Chen ${ }^{1}$, Zong-Guang Zhou ${ }^{3}$ and Jian-Kun Hu ${ }^{1 * \neq}$

${ }^{1}$ Department of Gastrointestinal Surgery, Laboratory of Gastric Cancer, State Key Laboratory of Biotherapy, Collaborative Innovation Center for Biotherapy, West China Hospital, Sichuan University, Chengdu, China, ${ }^{2}$ Engineering Research Center of Medical Information Technology, Ministry of Education, West China Hospital, Sichuan University, Chengdu, China,

${ }^{3}$ Department of Gastrointestinal Surgery, Laboratory of Digestive Surgery, State Key Laboratory of Biotherapy, Collaborative Innovation Center for Biotherapy, West China Hospital, Sichuan University, Chengdu, China

Background: There is controversy about the characteristics and prognostic implications of signet ring cell gastric cancers and non-signet ring cell gastric cancers.

Objective: This study aims to evaluate clinicopathological characteristics and prognoses of signet ring cell carcinoma (SRCC) and non-signet ring cell carcinoma (NSRCC) of stomach.

Methods: Studies compared between SRCC and NSRCC of the stomach after gastrectomy and published before September 1st, 2020, in the PubMed, Cochrane, and Embase databases, were identified systematically.

Results: A total of 2,865 studies were screened, and 36 studies were included, with 19,174 patients in the SRCC group and 55,942 patients in the NSRCC group. SRCC patients were younger in age $(P<0.001)$, less likely to be male patients $(P<0.001)$, more afflicted with upper third lesions $(P<0.001)$, and presenting with more Borrmann type IV tumors $(P=0.005)$ than NSRCC patients. Lymph nodes metastasis was similar between SRCC and NSRCC patients with advanced tumor stage (OR: 0.86, 95\% Cl: $0.67-1.10, P=0.23$ ), but lower in the SRCC than NSRCC patients with early tumor stage (OR: 0.73; 95\% Cl: 0.56-0.98, $P=0.02$ ). SRCC patients had comparable survival outcomes with NSRCC patients for early gastric cancers (HR: 1.05, 95\% Cl: 0.65-1.68, $P<0.001$ ) but had significantly poor prognosis for patients with advanced tumor stage (HR: 1.50, 95\% Cl: 1.28-1.76, $P<0.001$ ).

Conclusions: Signet ring cell carcinomas of the stomach are an increasingly common histopathological subtype of gastric cancers. These kinds of patients tend to be younger in age and more often female. Although, signet ring cell gastric cancer is a negative prognostic factor for patients with advanced stage. The difference is that for early stage of signet ring cell gastric cancers, it has low lymph nodes metastasis rate and comparable prognosis with non-signet ring cell cancers.

\footnotetext{
Keywords: prognosis, stage, sex, gastric cancer, signet ring cell
} 


\section{INTRODUCTION}

As one of the most common malignancies of the world, gastric cancer has a higher incidence in East Asian countries (1-4). The signet ring cell carcinoma (SRCC) of the stomach is one of histological subtypes of gastric adenocarcinomas. According to the World Health Organization (WHO) histological classification, the SRCC is an adenocarcinoma in which more than $50 \%$ of the tumor cells are scattered malignant cells containing intracytoplasmic mucin $(5,6)$. Besides, in the other histological classification of gastric cancers, SRCC is also can be classified as "diffused type" by Lauren classification and "undifferentiated type" by Japanese Gastric Cancer Classification $(7,8)$. Some studies reported that the SRCC of the stomach has unique and distinct clinicopathological characteristics with other types of carcinomas of the stomach (9-11). Some scholars have stated that the SRCC patients are further younger and include more female patients, while easily have lymph nodes metastasis and distal metastasis than non-signet ring cell carcinoma (NSRCC) patients (11-13). Besides, the prognostic implication of SRCC is still with controversies. Some studies reported that SRCC has better survival outcomes than NSRCC patients (14-16). Also, some studies have presented that the survival outcomes of SRCC were similar and even poorer than NSRCC patients (17-19). With respect to these controversies, some scholars attribute the differences to the different components of the tumor stage between SRCC and NSRCC patients (20).

In view of the foregoing, we performed this study aiming to systematically ascertain and comprehensively clarify the characteristics of signet ring cell gastric cancers. The primary outcomes of this study were the survival outcomes of SRCC patients. Other clinical characteristics, such as age, sex, and tumor stage, were also analyzed.

\section{METHODS AND MATERIALS}

\section{Search Strategy and Study selection}

A comprehensive literature search was performed in the Web of Knowledge, PubMed/Medline, Cochrane Collaborative Central Register of Controlled Trials, and Embase databases on September 1st, 2020, using the terms "gastric cancer," "gastric carcinoma," "gastric neoplasm," "signet ring cell," and restricted to

Literature Search: 2865 relevant articles identified

from PubMed, Embase The Cochrane Library ( $\mathrm{N}=2865)$

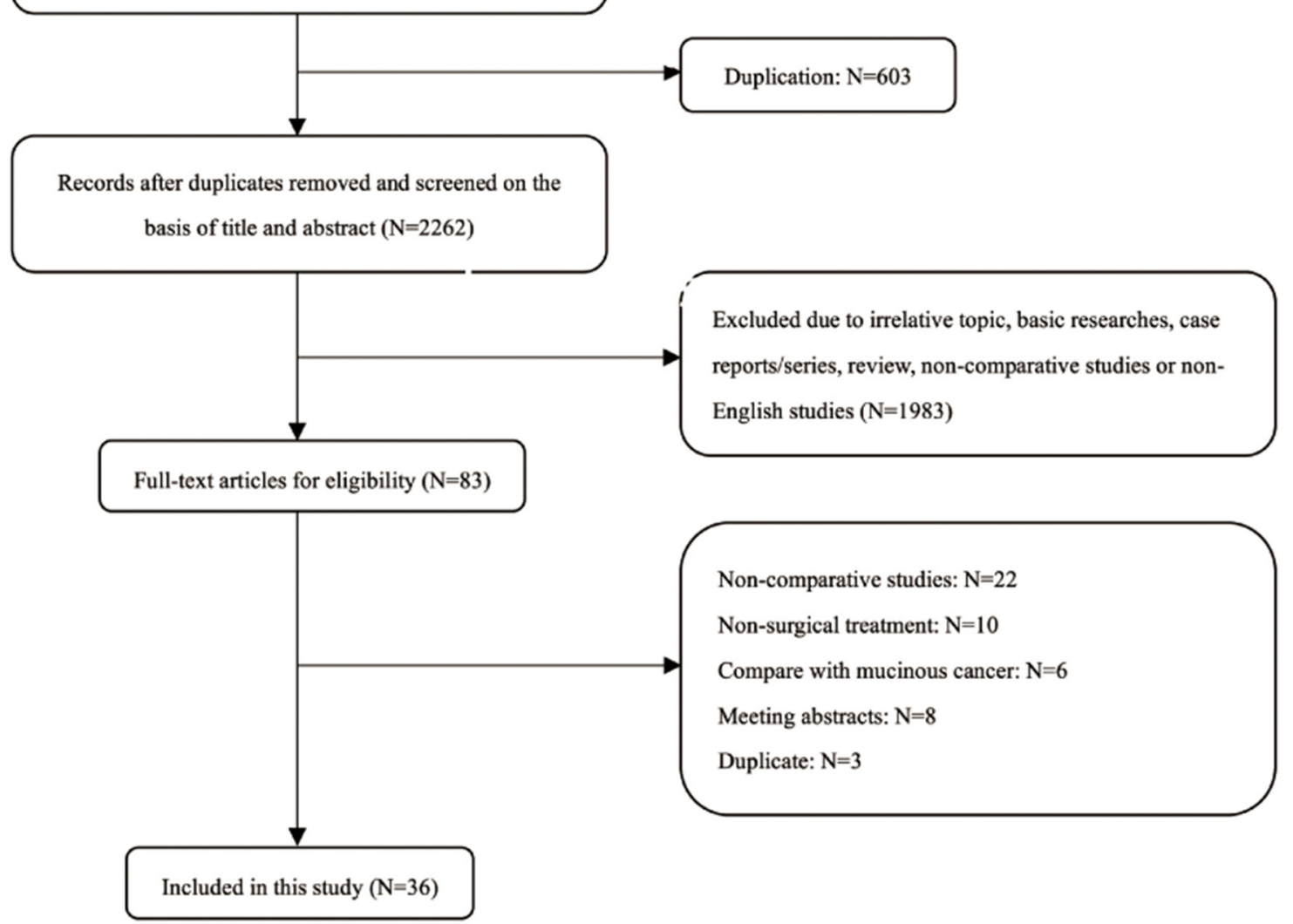

FIGURE 1 | Flow chart of literature selection. 
TABLE 1 | Characteristics of the included studies.

\begin{tabular}{|c|c|c|c|c|c|c|c|c|c|}
\hline References & Period & Country & No. of Patients & $\operatorname{SRCCN}=(\%)$ & NSRCC $N=(\%)$ & Stage & Pathological & Comparative group & NOS \\
\hline Maehara et al. (14) & 1965-1985 & Japan & 1,500 & $51(3.4)$ & 1,449 (96.6) & I-IV & WHO & NSRCC & 8 \\
\hline Kim et al. (24) & 1981-1991 & Korea & 3,702 & $450(12.1)$ & 3,252 (87.9) & I-IV & WHO & WD, MD, PD & 8 \\
\hline Otsuji et al. (15) & 1970-1994 & Japan & 1,498 & $154(10.3)$ & 1,344 (89.7) & I-IV & WHO & NSRCC & 7 \\
\hline Yokota et al. (17) & 1985-1995 & Japan & 683 & 93 (13.6) & $590(86.4)$ & I-IV & Japanese* & NSRCC & 5 \\
\hline Theuer et al. (25) & 1984-1994 & USA & 3,020 & $464(15.3)$ & $2,556(84.7)$ & $|-|||$ & WHO & NSRCC & 5 \\
\hline Kim et al. (18) & 1982-1999 & Korea & 2,358 & $204(8.7)$ & 2,154 (91.3) & I-IV & WHO & NSRCC & 8 \\
\hline Kunisaki et al. (26) & 1980-1998 & Japan & 1,113 & $174(15.6)$ & $939(84.4)$ & I-IV & WHO & NSRCC & 8 \\
\hline Li et al. (19) & 1987-2003 & Korea & 4,759 & $662(13.9)$ & 4,097 (86.1) & AGC & WHO & NSRCC & 9 \\
\hline Park et al. (27) & 1983-2002 & Korea & 2,275 & $251(11)$ & 2,024 (89) & I-IV & WHO & WMD, PD, MC & 9 \\
\hline Piessen et al. (28) & 1996-2007 & Fance & 159 & $59(37.1)$ & $100(62.9)$ & I-IV & WHO & NSRCC & 9 \\
\hline Lee et al. (29) & 2001-2008 & Korea & 1,362 & $448(32.8)$ & 914 (67.2) & EGC & WHO & NSRCC & 7 \\
\hline Zhang et al. (30) & 1993-2003 & China & 1,439 & $218(15.1)$ & $1,221(84.9)$ & I-IV & $\mathrm{WHO}$ & NSRCC & 8 \\
\hline Zheng et al. (31) & 1993-2006 & China & 511 & $39(7.6)$ & $472(92.4)$ & I-IV & WHO & WD, MD, PD & 6 \\
\hline Chiu et al. (32) & 1994-2006 & China & 2,439 & $505(20.7)$ & 1,934 (79.3) & I-IV & WHO & NSRCC & 9 \\
\hline Jiang et al. (13) & 1980-2004 & China & 2,315 & $211(9.1)$ & 2,104 (90.9) & I-IV & WHO & NSRCC & 9 \\
\hline Taghavi et al. (10) & 2004-2007 & USA & 10,246 & $2,666(26)$ & $7,580(74)$ & I-IV & WHO & NSRCC & 8 \\
\hline Gronnier et al. (16) & 1997-2010 & Fance & 421 & $104(24.7)$ & 317 (75.3) & EGC & WHO & NSRCC & 7 \\
\hline Huh et al. (33) & 1999-2005 & Korea & 2,052 & 540 (26.3) & 1,512 (73.7) & EGC & WHO & NSRCC & 7 \\
\hline Nafteux et al. (34) & 1990-2009 & Belgium & 920 & $114(12.3)$ & $806(87.7)$ & I-IV & WHO & NSRCC & 8 \\
\hline Shim et al. (20) & 1998-2005 & Korea & 2,643 & $377(14.2)$ & 2,266 (85.8) & $|-|||$ & $\mathrm{WHO}$ & NSRCC & 9 \\
\hline Bombat et al. (11) & 1990-2009 & USA & 569 & $210(36.9)$ & $359(63.1)$ & $|-|||$ & WHO & WMD, PD & 8 \\
\hline Kim et al. (12) & 1989-2000 & Korea & 2,050 & $345(16.8)$ & 1,705 (83.2) & EGC & WHO & WD, MD, PD & 7 \\
\hline Kwon et al. (9) & 1999-2009 & Korea & 769 & $108(14)$ & $661(86)$ & I-IV & WHO & WMD, PD & 9 \\
\hline Zu et al. (35) & 1997-2007 & China & 741 & $44(5.9)$ & $697(94.1)$ & AGC & WHO & WD, MD, PD & 7 \\
\hline Liu et al. (36) & 2000-2008 & China & 1,464 & $138(9.4)$ & 1,326 (90.6) & $|-|||$ & WHO & NSRCC & 9 \\
\hline Postlewait et al. (37) & 2000-2012 & USA & 768 & $312(40.6)$ & $456(59.4)$ & $|-|||$ & WHO & NSRCC & 9 \\
\hline Wang et al. (38) & 1994-2008 & China & 334 & $115(34.4)$ & $219(65.6)$ & EGC & WHO & NSRCC & 7 \\
\hline Guo et al. (39) & 2002-2013 & China & 1,067 & $198(18.5)$ & $869(81.5)$ & EGC & $\mathrm{WHO}$ & WMD, PD & 7 \\
\hline Kong et al. (40) & 1996-2012 & China & 480 & $90(18.7)$ & 390 (81.3) & $|-|||$ & WHO & NSRCC & 7 \\
\hline Lu et al. (41) & 1994-2013 & China & 2,199 & $354(16.1)$ & 1,845 (83.9) & I-IV & WHO & NSRCC & 7 \\
\hline Voron et al. (42) & 1997-2010 & Fance & 1,799 & 899 (49.9) & $900(50.1)$ & $\mathrm{I}-\mathrm{IV}$ & WHO & NSRCC & 9 \\
\hline Imamura et al. (43) & 2006-2012 & Japan & 746 & $190(25.4)$ & 556 (74.6) & EGC & WHO & NSRCC & 7 \\
\hline Lai et al. (44) & 1987-2005 & China & 2,873 & 745 (25.9) & $2,128(74.1)$ & EGC & WHO & WD, MD, PD & 6 \\
\hline Chon et al. (45) & 2001-2010 & Korea & 7,667 & 1,646 (21.4) & 6,021 (78.6) & $|-|||$ & WHO & WMD, PD & 9 \\
\hline Chen et al. (46) & 2002-2015 & China & 112 & $28(25.0)$ & $84(75.0)$ & EGC & WHO & NSRCC & 6 \\
\hline Chu et al. (47) & 2004-2015 & China & 6,063 & 5,968 (98.4) & $95(1.6)$ & I-IV & WHO & NSRCC & 9 \\
\hline
\end{tabular}

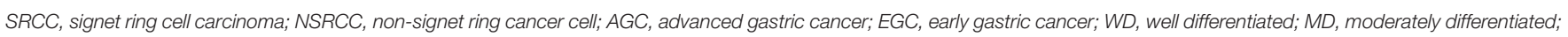
$P D$, poorly differentiated; WMD, well-moderately differentiated.

WHO, Histologic type of stomach cancer by WHO classification $(5,6)$.

*Japanese, The general rules for the gastric cancer study in surgery and pathology. Part I. Clinical classification (48).

title, abstract, and keywords. Previously published meta-analysis and systematic reviews were searched as well. Relevant articles were manually checked from the reference lists of the retrieved articles. Titles, abstracts, and subsequently full-text articles were screened by two authors (C Zhang and R Liu) based on the inclusion and exclusion criteria of this study.

\section{Inclusion and Exclusion Criteria}

The present study included those studies comparing SRCC with NSRCC (either well-controlled, moderated, and or/poorly differentiated cancers) on at least one outcome of interest.
Exclusion criteria included the following: (1) cancers compared only with mucinous carcinoma patients; (2) patients without gastrectomy; (3) patients with endoscopic mucosal resection (EMR) and endoscopic submucosal dissection (ESD); (4) review articles or case reports; (5) articles in other languages than English; and (6) incomplete or duplicate data.

\section{Data Extraction}

The data were independently extracted by two authors (C Zhang and R Liu) from the studies included. For each study, we recorded the name of first author, year of publication, country, study 
TABLE 2 | The meta-analysis of clinicopathological characteristics between SRCC and NSRCC patients.

\begin{tabular}{|c|c|c|c|c|c|c|c|c|c|}
\hline Characteristics & No. of study & No. of SRCC & No. of NSRCC & \multicolumn{2}{|c|}{ Test of heterogeneity } & Model & \multicolumn{3}{|c|}{ Meta-analysis } \\
\hline Sex (male) & 36 & 16,386 & 56,013 & 82 & $<0.001$ & Random & 0.55 & $0.50,0.61$ & $<0.001$ \\
\hline Locations (upper) & 25 & 10,902 & 48,408 & 89 & $<0.001$ & Random & 0.62 & $0.50,0.76$ & $<0.001$ \\
\hline Borrmann type (type-IV) & 9 & 2,447 & 11,416 & 92 & $<0.001$ & Random & 2.47 & $1.32,4.64$ & 0.005 \\
\hline Tumor size (cm) & 17 & 8,915 & 28,036 & 97 & $<0.001$ & Random & $-0.03^{*}$ & $-0.36,0.30$ & 0.87 \\
\hline Advanced stage (T2-T4 stage) & 17 & 7,602 & 30,718 & 97 & $<0.001$ & Random & 0.74 & $0.51,1.08$ & 0.12 \\
\hline Serosa invasive (T4 stage) & 19 & 8,527 & 35,167 & 87 & $<0.001$ & Random & 1.04 & $0.84,1.28$ & 0.71 \\
\hline Lymph nodes metastasis (N+ stage) & 29 & 14,352 & 44,271 & 94 & $<0.001$ & Random & 0.82 & $0.62,1.02$ & 0.07 \\
\hline Distal metastasis (M1 stage) & 8 & 6,543 & 14,222 & 18 & 0.29 & Random & 1.17 & $1.08,1.26$ & $<0.001$ \\
\hline
\end{tabular}

SRCC, signet ring cell carcinoma; NSRCC, non-signet ring cancer cell; OR, odds ratio; MD, mean difference.

"Mean difference (MD) was used to evaluated.

TABLE 3 | The meta-analysis of clinicopathological characteristics between SRCC and NSRCC patients based on tumor stage (EGC and AGC).

\begin{tabular}{|c|c|c|c|c|c|c|c|c|c|}
\hline Characteristics & No. of study & No. of SRCC & No. of NSRCC & \multicolumn{2}{|c|}{ Test of heterogeneity } & Model & \multicolumn{3}{|c|}{ Meta-analysis } \\
\hline EGC & 9 & 1,588 & 4,879 & 85 & $<0.001$ & Random & $-7.95^{*}$ & $-9.68,-6.16$ & $<0.001$ \\
\hline AGC & 7 & 1,419 & 11,202 & 84 & $<0.001$ & Random & $-3.89^{*}$ & $-5.99,-1.76$ & $<0.001$ \\
\hline \multicolumn{10}{|l|}{ Sex (male) } \\
\hline \multicolumn{10}{|c|}{ Tumor location (upper) } \\
\hline EGC & 10 & 2,908 & 10,180 & 64 & 0.0006 & Random & 0.57 & 0.41 .0 .79 & 0.007 \\
\hline AGC & 14 & 1,788 & 15,137 & 9 & 0.36 & Fixed & 0.75 & $0.64,0.87$ & $<0.001$ \\
\hline \multicolumn{10}{|l|}{$\mathbf{R}_{0}$ resection } \\
\hline AGC & 4 & 802 & 6,446 & 60 & 0.06 & Random & 0.80 & $0.65,0.99$ & 0.04 \\
\hline \multicolumn{10}{|c|}{ Serosa invasive (T4 stage) } \\
\hline AGC & 17 & 5,507 & 22,323 & 81 & $<0.001$ & Random & 1.22 & $0.99,1.49$ & 0.06 \\
\hline \multicolumn{10}{|c|}{ Lymph nodes metastasis ( $\mathrm{N}+$ stage) } \\
\hline EGC & 13 & 2,368 & 7,984 & 54 & 0.01 & Random & 0.73 & $0.56,0.95$ & 0.02 \\
\hline AGC & 10 & 1,788 & 15,137 & 74 & $<0.001$ & Random & 0.86 & $0.67,1.10$ & 0.23 \\
\hline \multicolumn{10}{|c|}{ Distal metastasis (M1 stage) } \\
\hline AGC & 5 & 933 & 7,737 & 57 & 0.05 & Random & 1.08 & $0.91,1.27$ & 0.37 \\
\hline
\end{tabular}

SRCC, signet ring cell carcinoma; NSRCC, non-signet ring cancer cell; AGC, advanced gastric cancer; EGC, early gastric cancer; OR, odds ratio; MD, mean difference.

"Mean difference (MD) was used to evaluated.

design, the time period of the included patients, classification of SRCC, sample size of SRCC and NSRCC and the definition of NSRCC. The following clinicopathological characteristics were also extracted: age, sex, tumor location, tumor size $(\mathrm{cm})$, differentiated degree of NSRCC group, Borrmann type, invasive depth of tumor ( $\mathrm{T}$ stage), status of lymph nodes metastasis $(\mathrm{N}$ stage), distal metastasis ( $\mathrm{M}$ stage), TNM stage and postoperative 5 -year overall survival. For those studies with more than one article and with duplicated data, only the article having the most complete data was included for analysis.

\section{Quality Assessment}

The quality of studies included was independently assessed by two authors (C Zhang and R Liu), according to the NewcastleOttawa Scale (NOS) (21). If there existed disagreement on the assessment, the consensus was reached by a discussion with 


\begin{tabular}{|c|c|c|c|c|c|c|c|}
\hline \multirow{2}{*}{$\begin{array}{l}\text { Study or Subgroup } \\
\text { Bombat } 2014\end{array}$} & \multirow{2}{*}{$\begin{array}{r}\text { log[Hazard Ratio] } \\
0.7419\end{array}$} & \multirow{2}{*}{$\begin{array}{r}\text { SE } \\
0.1683\end{array}$} & \multirow{2}{*}{$\begin{array}{r}\text { Weight } \\
3.8 \%\end{array}$} & \multirow{2}{*}{$\begin{array}{c}\begin{array}{c}\text { Hazard Ratio } \\
\text { IV, Random, 95\% CI }\end{array} \\
2.10[1.51,2.92]\end{array}$} & \multicolumn{2}{|c|}{$\begin{array}{c}\text { Hazard Ratio } \\
\text { IV, Random, 95\% CI }\end{array}$} & \\
\hline & & & & & & & \\
\hline Chiu 2010 & 0.0862 & 0.0701 & $4.3 \%$ & $1.09[0.95,1.25]$ & & 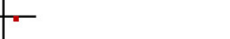 & \\
\hline Chon 2017 & -0.3417 & 0.0592 & $4.3 \%$ & $0.71[0.63,0.80]$ & - & & \\
\hline Chu 2020 & -0.3285 & 0.1192 & $4.1 \%$ & $0.72[0.57,0.91]$ & - & & \\
\hline Gronnier 2013 & -0.5108 & 0.3437 & $2.6 \%$ & $0.60[0.31,1.18]$ & & - & \\
\hline Hun 2012 & -0.478 & 0.2498 & $3.2 \%$ & $0.62[0.38,1.01]$ & & & \\
\hline Imamura 2016 & 0.3507 & 0.7932 & $0.9 \%$ & $1.42[0.30,6.72]$ & & & \\
\hline Jiang 2011 & -0.1985 & 0.0955 & $4.2 \%$ & $0.82[0.68,0.99]$ & & & \\
\hline Kim 2004 & 0.0198 & 0.1176 & $4.1 \%$ & $1.02[0.81,1.28]$ & & & \\
\hline Kong 2016 & 0.4824 & 0.236 & $3.3 \%$ & $1.62[1.02,2.57]$ & & & \\
\hline Kunisaki 2004 & -0.6162 & 0.7266 & $1.1 \%$ & $0.54[0.13,2.24]$ & & & \\
\hline Kwon 2014 & -0.3567 & 0.2032 & $3.6 \%$ & $0.70[0.47,1.04]$ & & & \\
\hline Li 2007 & 0.5539 & 0.1037 & $4.2 \%$ & $1.74[1.42,2.13]$ & & - & \\
\hline Liu 2015 & 0.4637 & 0.1351 & $4.0 \%$ & $1.59[1.22,2.07]$ & & & \\
\hline Lu 2016 & 0.2231 & 0.0606 & $4.3 \%$ & $1.25[1.11,1.41]$ & & - & \\
\hline Maehara 1992 & -0.1625 & 0.2707 & $3.1 \%$ & $0.85[0.50,1.44]$ & & & \\
\hline Nafteux 2014 & 0.7975 & 0.1185 & $4.1 \%$ & $2.22[1.76,2.80]$ & & 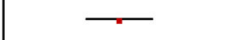 & \\
\hline Otsuji 1998 & -0.1393 & 0.1811 & $3.7 \%$ & $0.87[0.61,1.24]$ & & - & \\
\hline Park 2008 & 0.1823 & 0.0982 & $4.2 \%$ & $1.20[0.99,1.45]$ & & & \\
\hline Piessoon 2009 & 0.8065 & 0.2471 & $3.2 \%$ & $2.24[1.38,3.64]$ & & & \\
\hline Postlewait 2015 & 0.2311 & 0.0979 & $4.2 \%$ & $1.26[1.04,1.53]$ & & - & \\
\hline Shim 2014 & -0.0834 & 0.1542 & $3.9 \%$ & $0.92[0.68,1.24]$ & & - & \\
\hline Theuer 1999 & 0.2927 & 0.0649 & $4.3 \%$ & $1.34[1.18,1.52]$ & & - & \\
\hline Voron 2016 & 0.392 & 0.0623 & $4.3 \%$ & $1.48[1.31,1.67]$ & & $\rightarrow$ & \\
\hline Wang 2015 & 0.7608 & 0.032 & $4.4 \%$ & $2.14[2.01,2.28]$ & & $=$ & \\
\hline Yokota 1998 & 0.4318 & 0.1446 & $3.9 \%$ & $1.54[1.16,2.04]$ & & $\longrightarrow$ & \\
\hline Zheng 2010 & -0.7765 & 0.425 & $2.1 \%$ & $0.46[0.20,1.06]$ & & & \\
\hline Zu 2010 & -0.6931 & 0.3537 & $2.5 \%$ & $0.50[0.25,1.00]$ & & & \\
\hline \multirow{2}{*}{\multicolumn{5}{|c|}{$\begin{array}{l}\text { Heterogeneity: } \text { Tau }^{2}=0.17 ; \mathrm{Chi}^{2}=491.63, \mathrm{df}=27(\mathrm{P}<0.00001) ; \mathrm{I}^{2}=95 \% \\
\text { Test for overall effect: } \mathrm{Z}=1.47(\mathrm{P}=0.14)\end{array}$}} & & & \\
\hline & & & & & $\begin{array}{cc}0.2 & 0.5 \\
\text { Favours [experimental] }\end{array}$ & $\begin{array}{l}1 \\
11 \\
\text { Favours [control] }\end{array}$ & 5 \\
\hline
\end{tabular}

supervisors (WH Zhang and JK Hu). All of those studies included were ranked with a maximum of 9 points, studies with a Newcastle-Ottawa Scale score lower than 6 were considered as a moderate or low-quality study.

\section{Statistical Analysis}

The meta-analysis was performed according to the Cochrane guidelines (22). Category data were analyzed using the MantelHaenszel method. Continuous data were presented as the mean \pm standard deviation (SD) and analyzed by the inverse variance method. For those studies which only reported median values and ranges for continuous variables, the means and standard deviations were converted according to the method reported by Hozo et al. (23). The odds ratio (OR), mean difference (MD), and hazard ratio (HR) were used to evaluated dichotomous data, continuous data, and survival outcomes, respectively. All of the OR, HR, and MD were reported with 95\% confidence intervals (CIs).

Egger's regression and the funnel plot were used to test the publication bias. Heterogeneity was assessed using by the $I^{2}$ statistic. When $I^{2}<30 \%$, it was considered to be low heterogeneity; 30 and $<50 \%$ were considered to be moderate heterogeneity, and $\geq 50 \%$ was considered to be considerable heterogeneity. In the case of considerable heterogeneity, the random-effects model was used. For data with low or moderate heterogeneity, the fixed-effects model was used. Subgroup analyses based on different tumor stages were performed to identify potential differences between SRCC and NSRCC patients. The source of heterogeneity was explored with the meta-regression analysis. Possible parameters (publication year, sample size, study region, and tumor stage) were tested to explore potential origin of heterogeneity. All of the statistical analysis was performed by the "metafor" and "meta" packages of R software, version 3.2.4 (R Foundation for Statistical Computing, Vienna, Austria) and Review Manager software, version 5.3 (Cochrane, London, UK). A $P$-value $<0.05$ was considered statistically significant in the present study.

\section{RESULTS}

\section{Characteristics of the Studies}

According to the selection criteria, a total of 36 studies (9$20,24-47)$ with 75,116 patients $(19,174$ patients in the SRCC group and 55,942 patients in the NSRCC group) were included in the final meta-analysis (Figure 1). The general characteristics 


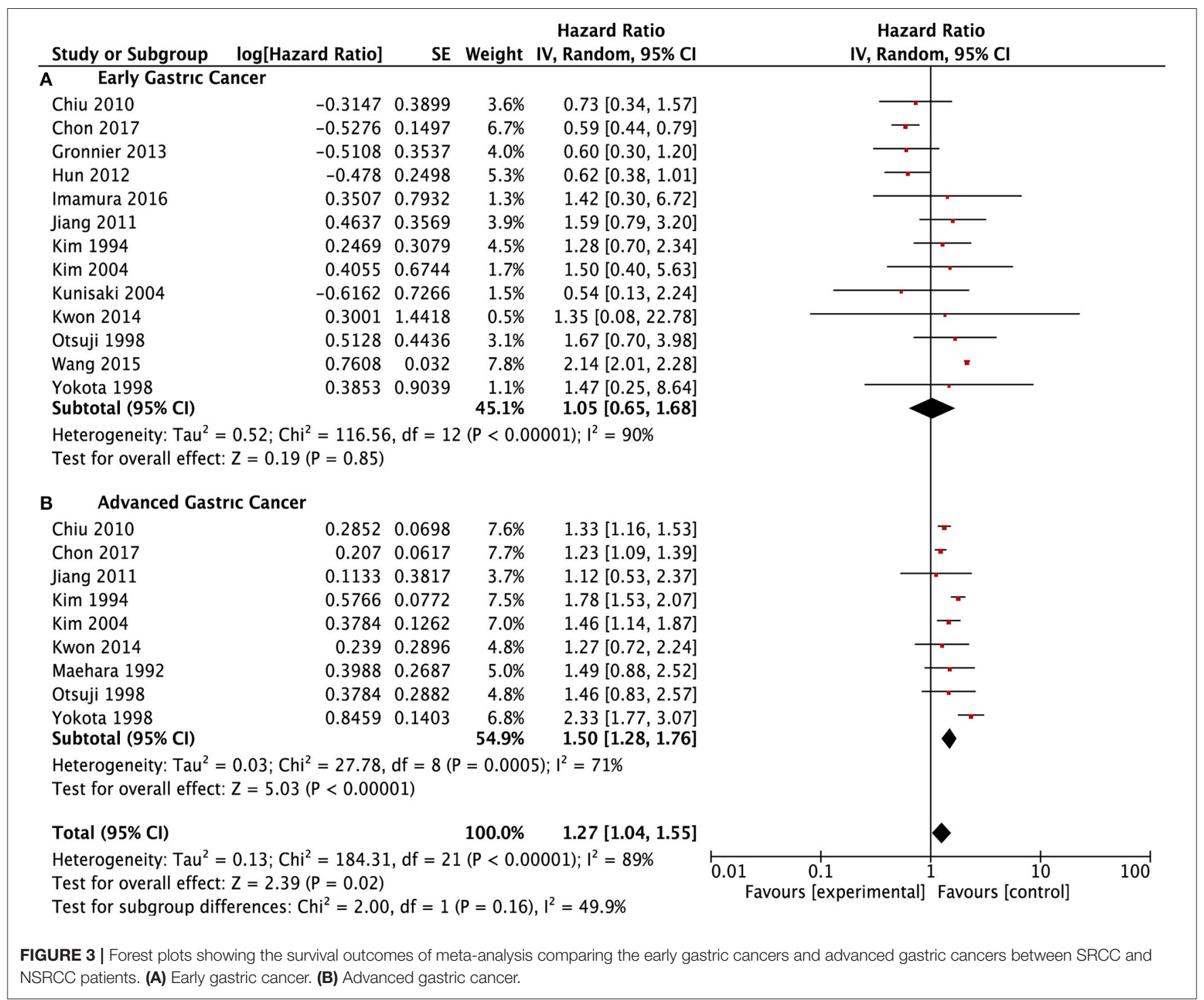

of those 36 studies included are presented in Table 1. These studies were from six countries and published from 1992 to 2020 and include gastric cancer patients underwent surgical treatment from 1965 to 2015 . Only 9 studies included early gastric cancer (EGC) patients $(12,16,29,33,38,39,43,44,46)$, 2 studies included only advanced gastric cancer (AGC) patients $(19,35), 18$ studies included Stage I-IV patients (9, 10, 13-15, 17, 18, 24, 26-28, 30-32, 34, 41, 42, 47), and 7 studies included stage I-III gastric cancer patients $(11,20,25,36,37,40,45)$. The majority of these studies adopted the WHO histological classification of gastric cancer in the diagnosis of $\operatorname{SRCC}(5,6)$, whereas only one study (17) used the Japanese classification (48). For the comparative group, 10 studies grouped the NSRCC gastric cancer patients according to the tumor-differentiated degree $(9,11,12,24,27,31,35,39,44,45)$, and the other 26 studies did not specify the composition-differentiated degree of NSRCC group. Besides, there were only one study presented that mucinous cancer was also included in the NSRCC group (27).

\section{Clinicopathological Characteristics}

We performed pooled analysis to compare the clinicopathological characteristics between the SRCC and NSRCC patients (Table 2). Finally, we found that SRCC patients have younger age $(\mathrm{MD}:-4.90,95 \% \mathrm{CI}-5.99$ to $-3.82 ; P<$ 0.001 ), fewer male patients (OR: $0.55,95 \%$ CI: $0.50-0.61, P<$ 0.001 ), less upper1 third lesions (OR: 0.62, 95\% CI: 0.50-0.76, $P<0.001$ ), more Borrmann-type IV tumors (OR: $2.47,95 \% \mathrm{CI}$ : $1.32-4.64, P=0.005)$, and patients with distal metastasis (OR: 1.17, 95\% CI: $1.08-1.26, P<0.001)$ with the comparison with NSRCC patients. There was no significant difference between SRCC and NSRCC patients with regard to radical surgical resection $(\mathrm{R} 0)$ rate $(P=0.25)$, tumor size $(P=0.87)$, proportion of advanced gastric cancers $(P=0.12)$, serosa invasive tumors $(P=0.71)$ and with lymph nodes metastasis $(P=0.07)$. 


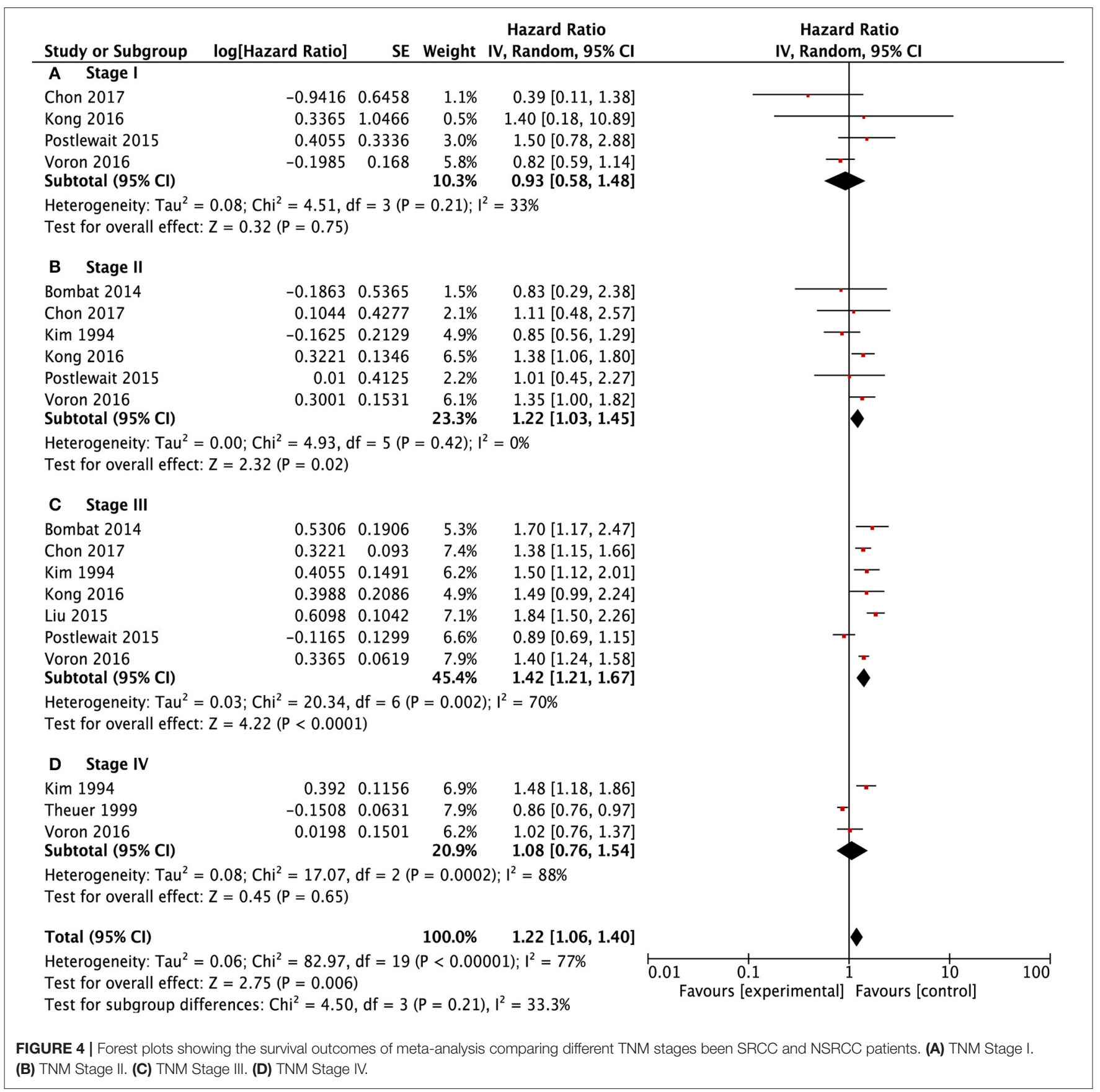

Due to consideration that tumor stage may have interaction with the clinicopathological characteristics, subgroup analyses were performed based on the clinicopathological characteristics of early gastric cancer (EGC) and advanced gastric cancer (AGC) (Table 3). The results of meta-analysis were that SRCC patients were of significantly younger age (EGC, MD: $-7.95,95 \% \mathrm{CI}$ : -9.68 to $-6.16, P<0.001$; AGC, MD: -3.89 , 95\% CI: -5.99 to $-1.76, P<0.001$ ), fewer male patients (EGC, OR: $0.57,95 \%$ CI: $0.43-0.75, P<0.001$; AGC, OR: 0.57, 95\% CI: $0.44-0.74$, $P<0.001$ ), fewer upper third tumors (EGC, OR: $0.57,95 \%$ CI: $0.41-0.79, P=0.007$; AGC, OR: 0.75 , 95\% CI: $0.64-0.87$,
$P<0.001)$ than NSRCC patients in both early and advanced gastric cancers. However, with regard to tumor size, there is no significant difference between SRCC and NSRCC patients in both EGC and AGC groups ( $P=0.83$ and $P=0.32$, respectively). We also found that there was no significant difference in lymph node metastasis between SRCC and NSRCC in advanced-stage patients (OR: $0.86,95 \% \mathrm{CI}: 0.67-1.10, P=0.23$ ), but SRCC patients had significantly fewer lymph nodes in metastasis than NSRCC patients with early tumor stage (OR: 0.73; 95\% CI: $0.56-0.98, P=0.02)$. Moreover, there is no difference in the ratio of serosa invasion (OR: 1.22, 95\% CI: $0.99-1.49, P=0.06)$ and 
TABLE 4 | Meta-regression for all included studies.

\begin{tabular}{llcc}
\hline Characteristics & & $\begin{array}{c}\text { Univariate } \\
\text { analysis } \\
\boldsymbol{P} \text {-value }\end{array}$ & $\begin{array}{c}\text { Multivariate } \\
\text { analysis } \\
\boldsymbol{P} \text {-value }\end{array}$ \\
\hline $\begin{array}{l}\text { Publication year } \\
\text { Sample size }\end{array}$ & $\begin{array}{l}1992-2020 \\
<1,000, \geq 1,000 \text { but } \\
\text { Region }\end{array}$ & 0.043 & 0.039 \\
Tumor stage & $\begin{array}{l}\text { China, Korea and Japan, } \\
\text { Europe and North America }\end{array}$ & 0.407 & \\
\hline & EGC and other & 0.042 & 0.427 \\
\hline
\end{tabular}

$O R$, odds ratio; $\mathrm{Cl}$, Confidence interval; $\mathrm{EGC}$, early gastric cancer.

distal metastasis (OR: 1.08; 95\% CI: 0.91-1.27, $P=0.37$ ) between SRCC and NSRCC of advanced stage patients.

\section{Survival Outcomes}

A total of 28 studies $(9,11,13-20,24-28,30-34,36-38,40-$ $42,45,47)$ reported data of survival outcomes and included prognostic meta-analysis (Figure 2). In the pooled analysis, we found that there was a positive survival difference in SRCC patients compared with NSRCC patients (HR: 1.14, 95\% CI: $0.96-1.34, P<0.001)$ and with significant heterogeneity $\left(I^{2}=\right.$ $95 \%, P<0.001)$. In view of the effect of the tumor stage on prognosis and different stage composition of different studies, subgroup survival analysis based on the different tumor stages was performed. For early gastric cancer patients, the metaanalysis included results of 13 studies $(9,13-18,24,26,32,33$, $38,45)$, and the results have shown that SRCC patients had similar survival outcomes with the NSRCC patients (HR: 1.05, 95\% CI: $0.65-1.68, P<0.001$ ) (Figure 3A). For the pooled analysis of advanced gastric cancer patients $(9,13-15,17,18,24$, $32,45)$, SRCC patients had significantly more negative survival outcomes than NSRCC patients (HR: 1.50, 95\% CI: 1.28-1.76, $P<0.001)\left(I^{2}=71 \%, P<0.001\right)$ (Figure 3B).

Meanwhile, we conducted subgroup survival analysis according to the TNM stage systems (Figure 4). SRCC and NSRCC had no significant difference in survival outcomes for stage I patients (HR: $0.93,95 \% \mathrm{CI}: 0.58-1.48, P=0.75$ ) and stage IV patients (HR: $1.08,95 \% \mathrm{CI}: 0.76-1.54, P=0.21$ ). There were significantly poorer survival outcomes of SRCC patients than NSRCC patients with TNM stage II (HR: 1.22, 95\% CI: $1.03-1.45, P=0.02$ ) and TNM stage III (HR: $1.42,95 \% \mathrm{CI}$ : $1.21-1.67, P<0.001)$.

\section{Publication Bias}

Meta-regression was performed to illuminate the origin of heterogeneity. We examined the year of publication, sample size, region of study, and tumor stage in a meta-regression model. The resulting analyses indicated that publication year $(P=0.039)$ and stage of the tumor $(P=0.002)$ were significant sources of heterogeneity for overall survival outcomes (Table 4).

The publication bias is evaluated by Funnel plots and Egger's test. The result found there was no publication bias for the early gastric cancer subgroup $(P=0.667)$ or the advanced gastric cancer subgroup $(P=0.629)$ for overall survival outcomes. The funnel plot and results of Egger's test of the early gastric cancer and advanced gastric cancer subgroup are presented in Figures 5A,B and Figures 6A,B.

\section{DISCUSSION}

Gastric cancer is one of the most common malignant diseases of the digestive system all over the world, and East Asian countries, such as Japan, Korea, and China have the highest incidence (1-4). Although the incidence of gastric cancer is declining, an increasing trend of signet ring cells in gastric cancer was obvious in recent decades (49). According to the previous report, signet ring cell carcinoma of the stomach has significantly different clinicopathological characteristics from other histological subtypes of gastric cancer (11-13). However, the prognostic meaning of SRCC is still controversial; for example, SRCC is a poor prognostic risk factor for overall survival outcomes (9-11). In the results of the present study, SRCC patients tended to be younger, more proportionally female, and more afflicted with middle and lower third tumors than NSRCC. As for survival outcomes, there were entirely different long-term survival outcomes of different tumor stages of SRCC when compared with NSRCC.

It is an acknowledgment that the SRCC patients are lower in age than NSRCC patients, and only a few studies reported that the mean age was similar between SRCC and NSRCC patients $(19,30$, 40). In the pooled analysis, age was significantly lower for SRCC patients than NSRCC patients. Besides, we also found earlystage cancer patients have greater age variance than advanced stage patients between the SRCC and NSRCC groups. Younger cohorts, tend to have a greater proportion of female patients, which is another clinicopathological characteristic of SRCC patients. However, the essential reason for a high proportion of female patients is unclear. Some studies have concluded that this phenomenon is due to the sex hormones of SRCC patients $(50,51)$.

We conducted an analysis of lymph node metastasis of SRCC and NSRCC patients. The results were that there was no significant difference for advanced gastric cancer patients between SRCC and NSRCC patients (OR: 0.86, 95\% CI: $0.67-1.10, P=0.23)$. However, for early gastric cancer patients, the results showed that SRCC patients had significantly lower incidence of lymph node metastasis than NSRCC patients. These results are consistent with results of the previous clinical study, in which Korean scholars deemed that the lymph node metastasis risk is low when the SRCC tumor was confined in the mucosa layer, but the risk of lymph node metastasis increases significantly, once the tumor penetrates the submucosa layer to the deep layers $(52,53)$.

The dispute about survival outcomes of SRCC patients is a major controversy when compared with NSRCC patients. During recent decades, scholars generally consider that SRCC patients have poorer survival outcomes than NSRCC patients, due to poor tumor behavior. However, the studies published in recent years have reported that the survival outcomes of SRCC patients 


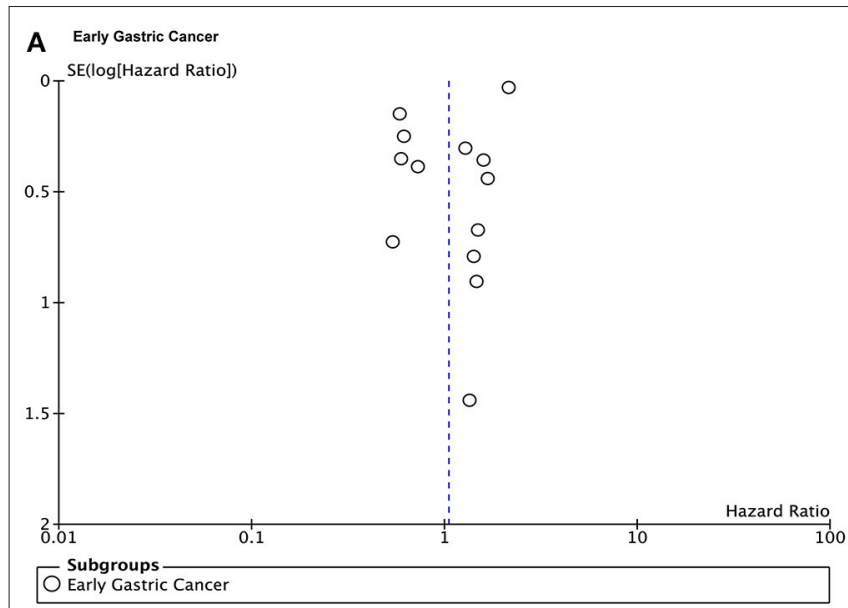

B Advanced Gastric Cancer

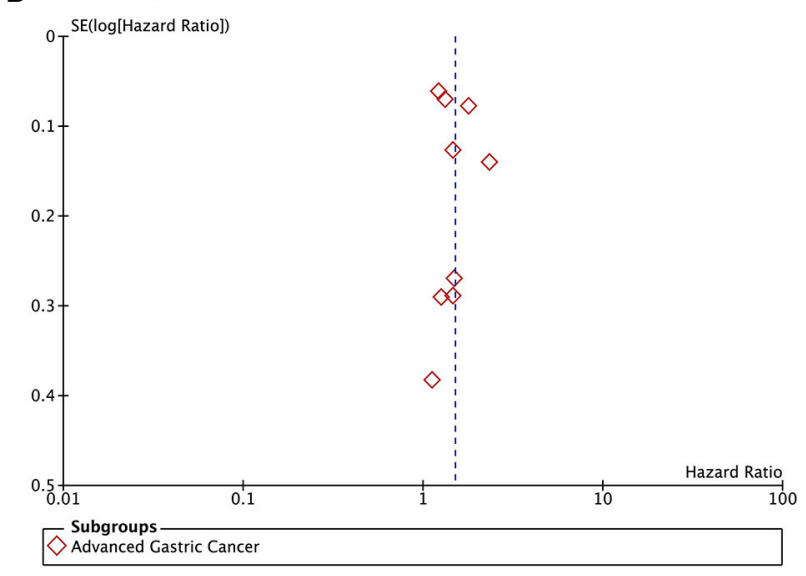

FIGURE 5 | Funnel plots of the overall survival outcomes. (A) Early gastric cancers. (B) Advanced gastric cancers.

should be evaluated and adjusted by tumor stage (20). For early gastric cancer, majority studies reported that SRCC was a good prognostic factor $(15,24,43,45)$. Besides, some also reported that the survival outcomes were comparable between SRCC and NSRCC patients $(13,17)$. In the pooled analysis of our study, SRCC patients have similar survival outcomes to those of NSRCC patients in both early gastric cancer patients and stageI patients and with low heterogeneity. At least we can show that, for early gastric cancers, the long-term prognosis of SRCC patients is not worse than that of NSRCC patients. It needs to be mentioned that the present study only included patients who underwent surgical treatment. Those SRCC and NSRCC patients who had endoscopic mucosa resection or endoscopic submucosa dissection are not included in this study.

For advanced gastric cancer patients, the prognostic meaning of signet ring cancer cell content is controversial. The general consensus is that the SRCC patients had poorer survival outcomes than the NSRCC patients (19). But does the evidence support this consensus? Some scholars claimed that SRCC patients had similar survival outcomes as NSRCC patients, and

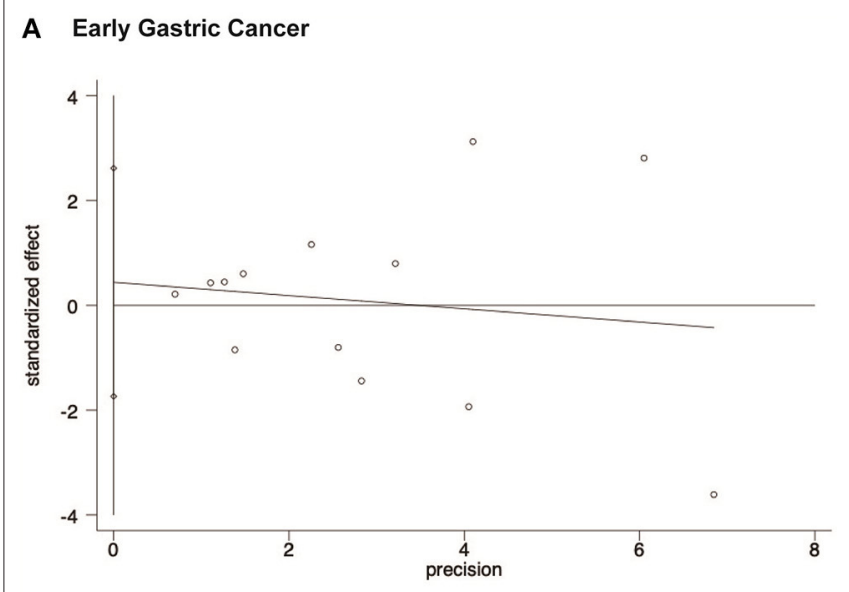

B Advanced Gastric Cancer

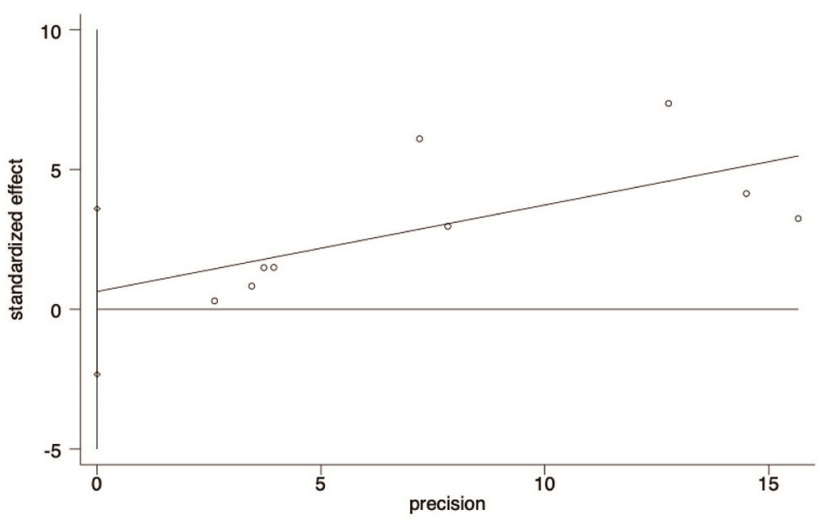

FIGURE 6 | Egger's test results showing that there is no publication bias of early gastric cancer subgroup and advanced gastric cancer subgroup for overall survival outcomes. (A) Early gastric cancers. (B) Advanced gastric cancers.

the survival evaluation between SRCC and NSRCC patients should adjust the differentiated degree and tumor stage (11, 45). A Korean study found that SRCC and NSRCC patients had similar survival outcomes after adjusting for the tumor stage by propensity score matching (20). In the pooled survival outcomes of advanced tumor stage patients, we found SRCC patients had significantly poorer survival outcomes than NSRCC patients (HR 1.27, 95\% 1.04-1.55). However, according to the TNM staging system of gastric cancer, advanced gastric cancers included tumors with $\mathrm{T} 2-4, \mathrm{~N}-/+, \mathrm{Mx}$ stages. Therefore, we performed a survival analysis according to the TNM stage, and we found that SRCC patients had similar survival outcomes in stage I and stage IV patients, and poorer survival outcomes in stage II and stage III SRCC patients with the comparison with NSRCC patients. Therefore, the prognosis of stage I and stage IV SRCC patients can be considered almost equal to that of NSRCC patients; but for the locally advanced stage (stages II-III) patients, 
the prognosis of SRCC patients is significantly poorer than for NSRCC patients.

Most of the studies included were retrospective studies. The quality of different retrospective studies varies, which is inevitable. Because of this, we use the NOS scoring system to evaluate the quality of each study included. Among the 36 retrospective studies included, two had a NOS score of 5 . We eliminated these two studies with relatively poor quality and conducted a subgroup analysis. In the end, we found that the results were not statistically different from those before the elimination. Through careful statistical analysis, 36 studies were finally included.

There is no consistent evidence about the appropriate chemotherapy treatment strategies for signet ring cell gastric carcinoma to improve prognosis. In previous studies, signet ring cell gastric carcinoma of the stomach was generally considered to be insensitive to chemotherapy, but there was no definite clinical evidence to support it. The comparison of chemosensitivity between signet ring cell gastric carcinoma and non-signet ring cell gastric carcinoma is still limited. Our previous study found that not all signet ring cell gastric cancers were insensitive to chemotherapy, and its chemosensitivity was related to the CLDN18-ARHGAP26/6 fusion gene (54). Li explored the survival of stage IIIII primary signet ring cell gastric carcinoma by adjuvant chemoradiotherapy (55). In this study, SRCC patients with stage II-III experienced improved overall survival after receiving adjuvant chemoradiotherapy, which provides several treatment implications. Therefore, more clinical trials will be needed to verify the conclusion.

However, there were several limitations in the present metaanalysis. First, all studies included are associated with long time spans and different versions of tumor stage classification. The stage migration and corresponding outcomes bias were exactly included among these studies and may result in the high heterogeneity in the pooled analysis. Second, the studies included were from different countries, the different treatment strategies from eastern and western countries were bias factors. Besides, different stage compositions between eastern and western countries also have an influence on the survival analysis. Third, all of the studies included are retrospective studies. The natural limitation and quality of the retrospective studies were another factor resulting in bias. Fourth, there is no indication of radical surgery for stage IV gastric cancer. And the reason for surgery is mostly because of complications caused by tumors such as bleeding and obstruction, rather than the tumor itself. So fewer patients with stage IV gastric cancer were included.

\section{REFERENCES}

1. Tsai MC, Wang CC, Lee HL, Peng CM, Yang TW, Chen HY, et al. Health disparities are associated with gastric cancer mortalityto-incidence ratios in 57 countries. World J Gastroenterol. (2017) 23:7881-7. doi: 10.3748/wjg.v23.i44.7881

2. Ferlay J, Soerjomataram I, Dikshit R, Eser S, Mathers C, Rebelo M, et al. Cancer incidence and mortality worldwide: sources, methods and
The heterogeneity test has been completed, and its purpose is to minimize the impact that heterogeneity may have on the quality of research and results.

\section{CONCLUSIONS}

Signet ring cell carcinoma of the stomach is one of the specific histological types of gastric carcinomas. The signet ring cell gastric cancer is predominantly found among younger people and females than non-signet ring cell gastric cancer. The prognostic features of signet ring cell carcinoma are significantly correlated with tumor stage. For gastric cancer patients with T1 stage or TNM stage-I, the prognosis of SRCC patients is comparable to that of NSRCC patients. For patients with T2-T4 stages and TNM stages II-III, the prognosis of SRCC patients is significantly worse than for NSRCC patients.

\section{DATA AVAILABILITY STATEMENT}

The original contributions presented in the study are included in the article/supplementary material, further inquiries can be directed to the corresponding author/s.

\section{AUTHOR CONTRIBUTIONS}

$\mathrm{W}-\mathrm{HZ}$ and J-KH designed the study. CZ, RL, W-HZ, XZC, KL, KY, X-LC, L-YZ, Z-XC, Z-GZ, and J-KH collected information and analyzed and interpreted the data. W-HZ and $\mathrm{J}-\mathrm{KH}$ supervised this study. All authors contributed to the article and approved the submitted version.

\section{FUNDING}

This work was supported by The National Natural Science Foundation of China (No. 81902437), Foundation of Science \& Technology Department of Sichuan Province (20YYJC3357), 1.3.5 Project for Disciplines of Excellence, West China Hospital, Sichuan University, Post-Doctor Research Project, West China Hospital, Sichuan University (2018HXBH010), and China Postdoctoral Science Foundation (2019M653418, 2020T130449).

\section{ACKNOWLEDGMENTS}

The authors thank the substantial work of the volunteer team of gastric cancer surgery (VOLTGA) based on the multidisciplinary team (MDT) of gastrointestinal tumors, West China Hospital, Sichuan University, China. 
5. Watanabe H, Jass JR, Sobin LH. Histological Typing of Oesophageal and Gastric Tumours. Berlin: Springer-Verlag (1990).

6. Bosman FT, Carneiro F, Hruban RH, Theise ND. WHO Classification of Tumours of the Digestive System. Lyon: International Agency for Research on Cancer (2010).

7. Lauren P. The two histological main types of gastric carcinoma: diffuse and socalled intestinal-type carcinoma. An attempt at a histo-clinical classification. Acta Pathol Microbiol Scand. (1965) 64:31-49. doi: 10.1111/apm.1965.64.1.31

8. Japanese Gastric Cancer A. Japanese classification of gastric carcinoma: 3rd English edition. Gastric Cancer. (2011) 14:10112. doi: 10.1007/s10120-011-0041-5

9. Kwon KJ, Shim KN, Song EM, Choi JY, Jung SA. Clinicopathological characteristics and prognosis of signet ring cell carcinoma of the stomach. Gastric Cancer. (2014) 17:43-53. doi: 10.1007/s10120-013-0234-1

10. Taghavi S, Jayarajan SN, Davey A, Willis AI. Prognostic significance of signet ring gastric cancer. J Clin Oncol. (2012) 30:3493-8. doi: 10.1200/JCO.2012.42.6635

11. Bamboat ZM, Tang LH, Vinuela E, Kuk D, Strong VE. Stage-stratified prognosis of signet ring cell histology in patients undergoing curative resection for gastric adenocarcinoma. Ann Surg Oncol. (2014) 21:167885. doi: 10.1245/s10434-013-3466-8

12. Kim BS, Oh ST, Yook JH, Kim BS. Signet ring cell type and other histologic types: differing clinical course and prognosis in T1 gastric cancer. Surgery. (2014) 155:1030-5. doi: 10.1016/j.surg.2013.08.016

13. Jiang C-GMD, Wang Z-NMD, Sun ZMD, Liu F-NMD, Yu MMD, Xu HMMD. Clinicopathologic characteristics and prognosis of signet ring cell carcinoma of the stomach: results from a chinese mono-institutional study. J Surg Oncol. (2011) 103:700-3. doi: 10.1002/jso.21878

14. Maehara Y, Sakaguchi Y, Moriguchi S, Orita H, Korenaga D, Kohnoe S, et al. Signet ring cell carcinoma of the stomach. Cancer. (1992) 69:1645-50. doi: 10. 1002/1097-0142(19920401)69:7<1645::AID-CNCR2820690702>3.0.CO;2-X

15. Otsuji E, Yamaguchi T, Sawai K, Takahashi T. Characterization of signet ring cell carcinoma of the stomach. J Surg Oncol. (1998) 67:216-20. doi: 10.1002/ (SICI) 1096-9098(199804)67:4<216::AID-JSO2>3.0.CO;2-B

16. Gronnier C, Messager M, Robb WB, Thiebot T, Louis D, Luc G, et al. Is the negative prognostic impact of signet ring cell histology maintained in early gastric adenocarcinoma? Surgery. (2013) 154:10939. doi: 10.1016/j.surg.2013.05.020

17. Yokota T, Kunii Y, Teshima S, Yamada Y, Saito T, Kikuchi S, et al. Signet ring cell carcinoma of the stomach: a clinicopathological comparison with the other histological types. Tohoku J Exp Med. (1998) 186:12130. doi: $10.1620 /$ tjem.186.121

18. Kim DY, Park YK, Joo JK, Ryu SY, Kim YJ, Kim SK, et al. Clinicopathological characteristics of signet ring cell carcinoma of the stomach. ANZ J Surg. (2004) 74:1060-4. doi: 10.1111/j.1445-1433.2004.03268.x

19. Li C, Kim S, Lai JF, Hyung WJ, Choi WH, Choi SH, et al. Advanced gastric carcinoma with signet ring cell histology. Oncology. (2007) 72:648. doi: $10.1159 / 000111096$

20. Shim J-HMD, Song K-YMD, Kim H-HMD, Han S-UMD, Kim MCMD, Hyung W-JMD, et al. Signet ring cell histology is not an independent predictor of poor prognosis after curative resection for gastric cancer: a propensity analysis by the KLASS group. Medicine. (2014) 93:e136. doi: 10.1097/MD.0000000000000136

21. Stang A. Critical evaluation of the Newcastle-Ottawa scale for the assessment of the quality of nonrandomized studies in meta-analyses. Eur J Epidemiol. (2010) 25:603-5. doi: 10.1007/s10654-010-9491-z

22. Higgins JPT, Thomas J, Chandler J, Cumpston M, Li T, Page MJ, et al. (editors.). Cochrane Handbook for Systematic Reviews of Interventions. 2nd ed. Chichester: John Wiley \& Sons (2019).

23. Hozo SP, Djulbegovic B, Hozo I. Estimating the mean and variance from the median, range, and the size of a sample. BMC Med Res Methodol. (2005) 5:13. doi: $10.1186 / 1471-2288-5-13$

24. Kim JP, Kim SC, Yang HK. Prognostic significance of signet ring cell carcinoma of the stomach. Surg Oncol. (1994) 3:2217. doi: 10.1016/0960-7404(94)90037-X

25. Theuer CP, Nastanski F, Brewster WR, Butler JA, Anton-Culver H. Signet ring cell histology is associated with unique clinical features but does not affect gastric cancer survival. Am Surg. (1999) 65:915-21.
26. Kunisaki C, Shimada H, Nomura M, Matsuda G, Otsuka Y, Akiyama H. Therapeutic strategy for signet ring cell carcinoma of the stomach. Br J Surg. (2004) 91:1319-24. doi: 10.1002/bjs.4637

27. Park JM, Jang YJ, Kim JH, Park SS, Park SH, Kim SJ, et al. Gastric cancer histology: clinicopathologic characteristics and prognostic value. J Surg Oncol. (2008) 98:520-5. doi: 10.1002/jso.21150

28. Piessen G, Messager M, Leteurtre E, Jean-Pierre T, Mariette C. Signet ring cell histology is an independent predictor of poor prognosis in gastric adenocarcinoma regardless of tumoral clinical presentation. Ann Surg. (2009) 250:878-87. doi: 10.1097/SLA.0b013e3181b21c7b

29. Lee JH, Choi IJ, Kook MC, Nam BH, Kim YW, Ryu KW. Risk factors for lymph node metastasis in patients with early gastric cancer and signet ring cell histology. Br J Surg. (2010) 97:732-6. doi: 10.1002/bjs.6941

30. Zhang M, Zhu G, Zhang H, Gao H, Xue Y. Clinicopathologic features of gastric carcinoma with signet ring cell histology. J Gastrointest Surg. (2010) 14:601-6. doi: 10.1007/s11605-009-1127-9

31. Zheng HC, Zheng YS, Xia P, Xu XY, Xing YN, Takahashi H, et al. The pathobiological behaviors and prognosis associated with Japanese gastric adenocarcinomas of pure WHO histological subtypes. Histol Histopathol. (2010) 25:445-52. doi: 10.14670/HH-25.445

32. Chiu CT, Kuo CJ, Yeh TS, Hsu JT, Liu KH, Yeh CN, et al. Early signet ring cell gastric cancer. Digest Dis Sci. (2011) 56:1749-56. doi: 10.1007/s10620-010-1487-8

33. Huh CW, Jung DH, Kim JH, Lee YC, Kim H, Kim H, et al. Signet ring cell mixed histology may show more aggressive behavior than other histologies in early gastric cancer. J Surg Oncol. (2013) 107:124-9. doi: 10.1002/jso.23261

34. Nafteux PR, Lerut TE, Villeneuve PJ, Dhaenens JM, Hertogh DG, Moons J, et al. Signet ring cells in esophageal and gastroesophageal junction carcinomas have a more aggressive biological behavior. Ann Surg. (2014) 260:10239. doi: $10.1097 /$ SLA.0000000000000689

35. Zu H, Wang H, Li C, Xue Y. Clinicopathologic characteristics and prognostic value of various histological types in advanced gastric cancer. Int J Clin Exp Pathol. (2014) 7:5692-700.

36. Liu X, Cai H, Sheng W, Lin Y, Long Z, Shi Y, et al. Clinicopathological characteristics and survival outcomes of primary signet ring cell carcinoma in the stomach: retrospective analysis of single center database. PLOS ONE. (2015) 10:e0144420. doi: 10.1371/journal.pone.0144420

37. Postlewait LM, Squires MH, Kooby DA, Poultsides GA, Weber SM, Bloomston $\mathrm{M}$, et al. The prognostic value of signet-ring cell histology in resected gastric adenocarcinoma. Ann Surg Oncol. (2015) 22:8329. doi: 10.1245/s10434-015-4724-8

38. Wang Z, Zhang X, Hu J, Zeng W, Zhou Z. Clinicopathological features and outcomes in patients undergoing radical resection for early gastric cancer with signet ring cell histology. J Visceral Surg. (2015) 152:35761. doi: 10.1016/j.jviscsurg.2015.09.021

39. Guo CG, Zhao DB, Liu Q, Zhou ZX, Zhao P, Wang GQ, et al. Risk factors for lymph node metastasis in early gastric cancer with signet ring cell carcinoma. J Gastrointest Surg. (2015) 19:1958-65. doi: 10.1007/s11605-015-2915-Z

40. Kong P, Wu R, Yang C, Geng Q, Liu J, Chen S, et al. Prognostic impact of the signet ring cell type in node-negative gastric cancer. Sci Rep. (2016) 6:06. doi: $10.1038 /$ srep26313

41. Lu MMD, Yang ZP, Feng QBM, Mei Y, Tang J. The characteristics and prognostic value of signet ring cell histology in gastric cancer: a retrospective cohort study of 2199 consecutive patients. Medicine. (2016) 95:e4052. doi: 10.1097/MD.0000000000004052

42. Voron T, Messager M, Duhamel A, Lefevre J, Paye F. Is signet-ring cell carcinoma a specific entity among gastric cancers? Gastr Cancer. (2016) 19:1027-40. doi: 10.1007/s10120-015-0564-2

43. Imamura $\mathrm{T}$, Komatsu S, Ichikawa D, Kawaguchi T, Kosuga T, Okamoto K, et al. Early signet ring cell carcinoma of the stomach is related to favorable prognosis and low incidence of lymph node metastasis. J Surg Oncol. (2016) 114:607-12. doi: 10.1002/jso.24377

44. Lai JF, Xu WN, Noh SH, Lu WQ. Effect of World Health Organization (WHO) histological classification on predicting lymph node metastasis and recurrence in early gastric cancer. Med Sci Monit. (2016) 22:314753. doi: 10.12659/MSM.897311

45. Chon HJ, Hyung WJ, Kim C, Park S, Kim JH, Park CH, et al. Differential prognostic implications of gastric signet ring cell carcinoma: stage adjusted 
analysis from a single high-volume center in Asia. Ann Surg. (2017) 265:94653. doi: $10.1097 /$ SLA. 0000000000001793

46. Chen J, Cai R, Ren G, Zhao J, Li H, Guo C, et al. Differences in clinicopathological characteristics and computed tomography findings between signet ring cell carcinoma and nonsignet ring cell carcinoma in early and advanced gastric cancer. Cancer Med. (2018) 7:1160-9. doi: $10.1002 / \mathrm{cam} 4.1417$

47. Chu YX, Gong HY, Hu QY, Song QB. Adenosquamous carcinoma may have an inferior prognosis to signet ring cell carcinoma in patients with stages I and II gastric cancer. World J Gastrointest Onco. (2020) 12:101-12. doi: 10.4251/wjgo.v12.i1.101

48. Kajitani T. The general rules for the gastric cancer study in surgery and pathology. Part I. Clinical classification. Jpn J Surg. (1981) 11:12739. doi: $10.1007 / \mathrm{BF} 02468883$

49. Henson DE, Dittus C, Younes M, Nguyen H, Albores-Saavedra J. Differential trends in the intestinal and diffuse types of gastric carcinoma in the United States, 1973-2000: increase in the signet ring cell type. Arch Pathol Lab Med. (2004) 128:765-70. doi: 10.5858/2004-128-765DTITIA

50. Matsui M, Kojima O, Kawakami S, Uehara Y, Takahashi T. The prognosis of patients with gastric cancer possessing sex hormone receptors. Surg Today. (1992) 22:421-5. doi: 10.1007/BF003 08791

51. Kim HW, Kim JH, Lim BJ, Kim H, Kim H, Park JJ, et al. Sex disparity in gastric cancer: female sex is a poor prognostic factor for advanced gastric cancer. Ann Surg Oncol. (2016) 23:4344-51. doi: 10.1245/s10434-0165448-0
52. Kim YH, Kim JH, Kim H, Kim H, Lee YC, Lee SK, et al. Is the recent WHO histological classification for gastric cancer helpful for application to endoscopic resection? Gastr Cancer. (2016) 19:86975. doi: 10.1007/s10120-015-0538-4

53. Park JM, Kim SW, Nam KW, Cho YK, Lee IS, Choi MG, et al. Is it reasonable to treat early gastric cancer with signet ring cell histology by endoscopic resection? Analysis of factors related to lymph-node metastasis. Eur J Gastroenterol Hepatol. (2009) 21:1132-5. doi: 10.1097/MEG.0b013e32832a21d8

54. Shu Y, Zhang W, Hou Q, Zhao L, Zhang S, Zhou J, et al. Prognostic significance of frequent CLDN18-ARHGAP26/6 fusion in gastric signet-ring cell cancer. Nat Commun. (2018) 9:2447. doi: 10.1038/s41467-018-04907-0

55. Li Y, Zhu Z, Ma F, Xue L, Tian Y. Improving survival of stage II-III primary gastric signet ring cell carcinoma by adjuvant chemoradiotherapy. Cancer Med. (2020) 9:6617-28. doi: 10.1002/cam4.3342

Conflict of Interest: The authors declare that the research was conducted in the absence of any commercial or financial relationships that could be construed as a potential conflict of interest.

Copyright (๑ 2021 Zhang, Liu, Zhang, Chen, Liu, Yang, Chen, Zhao, Chen, Zhou and $H u$. This is an open-access article distributed under the terms of the Creative Commons Attribution License (CC BY). The use, distribution or reproduction in other forums is permitted, provided the original author(s) and the copyright owner(s) are credited and that the original publication in this journal is cited, in accordance with accepted academic practice. No use, distribution or reproduction is permitted which does not comply with these terms. 